\title{
Uncommon forms of diabetes
}

Diabetes mellitus is a common condition which all clinicians will encounter in their clinical practice. The most common form is type 2 diabetes followed by type 1 diabetes. However, there are many other atypical forms of diabetes which are important for a clinician to consider as it can impact on the diagnosis and their management.

This article focuses on maturity onset diabetes of the young (MODY), latent autoimmune diabetes in adults (LADA), ketosis-prone diabetes and other secondary forms of diabetes such as pancreatic cancer and haemochromatosis. We briefly describe the key clinical features of these forms of diabetes and their investigations and treatment.

\section{Introduction}

In the UK, around $90 \%$ of people with diabetes have type 2 diabetes (T2D), around $8 \%$ have type 1 diabetes (T1D) and around $2 \%$ have other forms of diabetes.

Typically, we see T1D present in a young, lean patient with marked symptoms of polyuria, polydipsia, weight loss and diabetic ketoacidosis (DKA). In T2D, they are usually older, overweight and they are usually managed with oral medications initially. We should consider other forms of diabetes if the presentation is not typical; for example, we should consider maturity onset diabetes of the young (MODY) in a young, lean person with mild hyperglycaemia and a strong family history of diabetes diagnosed at a young age. We should think about latent autoimmune diabetes in adults (LADA) in a middle aged, lean patient with hyperglycaemia. We should consider ketosis-prone diabetes in a an overweight, non-White patient with DKA.

Here, we will focus on MODY, LADA, ketosis-prone diabetes and some secondary causes of diabetes. Other forms of diabetes are listed in Table 1. ${ }^{2}$

\section{Maturity onset diabetes of the young}

MODY is a group of monogenic beta-cell disorders, also known as monogenic diabetes. They are characterised by young age of onset (usually $<25$ years), autosomal dominant transmission, absence of autoimmune markers, absence of insulin resistance

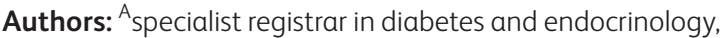
Barts Health NHS Trust, London, UK; ${ }^{B}$ consultant in diabetes and metabolism and honorary senior lecturer, Barts Health NHS Trust, London, UK and insulin independence. It is estimated to account for $1 \%-2 \%$ of patients diagnosed with diabetes and, in the UK, the prevalence of MODY is estimated to be at 108 cases per million. ${ }^{3}$ However, it may be a significant underestimate and these figures are not accurate until large population screening studies are performed. The most common mutations are hepatocyte nuclear factor-1alpha (HNF1 $\alpha ; 52 \%)$, glucokinase (GCK; $32 \%)$ and $H N F 4 \alpha(10 \%)$, see Table 2. $^{3}$

\section{Hepatocyte nuclear factor-1-alpha gene}

Formerly called MODY3, mutations on the HNF1 $\alpha$ gene on chromosome 3 are associated with a progressive defect of insulin secretion. ${ }^{4}$ Mutations here also result in low renal threshold for glucose and thus mutation carriers have detectable glycosuria. ${ }^{5}$

\section{Key points}

Suspect other uncommon forms of diabetes if the clinical picture does not fit type 1 or type 2 diabetes. History, family history and phenotype of patient is useful. Screen for pancreatic cancer if there is new onset type 2 diabetes in older people with dramatic weight loss and features of exocrine insufficiency.

If a patient presents with or develops diabetic ketoacidosis (DKA), they should be discharged on insulin; this includes ketosis-prone diabetes (in this case, their insulin requirement can be re-evaluated in an outpatient setting after the acute episode).

Useful investigations to diagnose different forms of diabetes are glucose paired with C-peptide and diabetes autoantibodies.

People with uncommon forms of diabetes can develop microvascular and macrovascular complications of diabetes and regular screening of complications should still be carried out.

Contact the local diabetes team at an early stage for any unusual presentation of diabetes.

KEYWORDS: uncommon, atypical, diabetes, LADA, MODY

DOI: 10.7861/clinmed.2021-0369 


Table 1. Aetiological classification of diabetes
mellitus

People with HNF-1 MODY can develop microvascular and macrovascular complications seen in T1D and T2D and, in addition, have an increased risk of cardiovascular mortality. ${ }^{6}$

They are exquisitely sensitive to sulphonylureas and often maintain excellent glycaemic control for years on these medications, with some patients eventually requiring insulin therapy.

\section{Glucokinase gene}

Formerly called MODY2, the GCK gene is found on chromosome 7. This mutation results in a higher threshold for glucose stimulated insulin secretion. Insulin secretion remains regulated and thus hyperglycaemia is often mild and stable. Patients are asymptomatic and hyperglycaemia is often found incidentally or during pregnancy. ${ }^{4}$

Diabetes-related microvascular complications are not observed. ${ }^{7}$

There are no large studies assessing long term macrovascular outcomes, but GCK mutation carriers appear to have normal cardiovascular risk profiles. ${ }^{8}$

Treatment is not needed outside of pregnancy. During pregnancy, women are monitored closely, and occasionally insulin therapy is used, but if the fetus is macrosomic, the mainstay of treatment is early delivery.

\section{Hepatocyte nuclear factor-4-alpha gene}

Formerly known as MODY1, the HNF4 $\alpha$ gene is found on chromosome 20 and is expressed both in the liver and in pancreatic beta cells. It functions to regulate positively the activity of HNF1 $\alpha$ and is therefore similarly associated with an abnormal insulin secretory response to glucose. ${ }^{9}$ Unlike $H N F 1 \alpha$, mutation carriers of $H N F 4 \alpha$ have normal renal glucose threshold.

Similar to $H N F 1 \alpha$, patients can develop microvascular and macrovascular complications and are also extremely sensitive to sulphonylureas.

\section{Investigations}

Clinicians should suspect MODY if patients are young, have a strong family history of diabetes diagnosed at a young age $(<30$ years old), have no features suggestive of insulin resistance and are not insulin-dependent. These investigations are helpful to aid clinical suspicion: negative autoantibody profile (islet cell cytoplasmic autoantibodies (ICA), glutamic acid decarboxylase autoantibodies (GAD65), insulinoma-associated-2 autoantibodies (IA2), zinc transporter-8 autoantibodies (ZnT8)) and sufficient C-peptide levels in comparison with paired serum glucose levels. High sensitivity $C$ reactive protein, which is under transcriptional control by $H N F 1 \alpha$, has been seen to be lower in patients with $H N F 1 \alpha$ mutations. Given its modest cost and availability, they could be used as a biomarker to identify those with $H N F 1 \alpha$ MODY. ${ }^{4}$ There is also a role for urinary C-peptide creatinine ratio as a practical outpatient tool in discriminating between HNF1 $\alpha / H N F 4 \alpha$ MODY ( $>0.2 \mathrm{nmol} / \mathrm{mmol}$ ) and T1D of more than 5 years duration. ${ }^{10}$ There is an online MODY probability calculator which can aid to quantify our clinical suspicion of MODY, and it can be found on: www.diabetesgenes.org.

Ultimately, diagnosis is via MODY genetic testing and recently this has been easier to access in the UK. Physicians should refer to their local diabetes or clinical genetics team to discuss this. A MODY genetic testing form can also be found on the given website.

\section{Latent autoimmune diabetes in adults}

LADA is a heterogeneous condition which shares characteristics of both T1D and T2D. Typically, LADA presents like T2D but is associated with progression to early insulin therapy. It is debated whether LADA is a distinct entity, or simply part of the spectrum of T1D. Studies suggest that LADA accounts for $2 \%-12 \%$ of adultonset diabetes. ${ }^{11}$

Compared with T2D, people with LADA tend to be younger, leaner and have a personal or family history of autoimmune 
Table 2. Comparison of maturity onset diabetes of the young subtypes

\begin{tabular}{llll} 
MODY mutation & HNF1 $\alpha$ (previously MODY3) & GCK (previously MODY2) & HNF4 $\alpha$ (previously MODY1) \\
Estimated frequency & $52 \%$ & $32 \%$ & $10 \%$ \\
Chromosome affected & 3 & 7 & 20 \\
Defect & $\begin{array}{l}\text { Progressive reduced insulin } \\
\text { secretory response to glucose }\end{array}$ & $\begin{array}{l}\text { Higher threshold for glucose } \\
\text { stimulated insulin }\end{array}$ & $\begin{array}{l}\text { Regulates activity of HNF1 } \alpha \text { therefore } \\
\text { also show abnormal insulin secretory } \\
\text { response to glucose }\end{array}$ \\
Clinical features & $\begin{array}{l}\text { Low renal threshold for glucose } \\
\text { (glycosuria) }\end{array}$ & $\begin{array}{l}\text { Mild, stable and asymptomatic; } \\
\text { hyperglycaemia often found } \\
\text { incidentally }\end{array}$ & Normal renal threshold for glucose \\
Risk of microvascular/ & Yes & Not observed & Yes \\
macrovascular disease & Sulphonylureas, but may & Not required; will need close & Sulphonylureas, but may progress to \\
Optimal treatment & monitoring during pregnancy & insulin \\
\hline
\end{tabular}

$H N F 1 \alpha=$ hepatocyte nuclear factor-1-alpha; GCK = glucokinase; $H N F 4 \alpha=$ hepatocyte nuclear factor-4-alpha.

disease. Features of the metabolic syndrome tend to be present in a similar or higher frequency in LADA compared with T1D. There is considerable heterogeneity and is sometimes phenotypically and characteristically indistinguishable from T1D or T2D. ${ }^{12}$ It is thought that LADA is a more insidious presentation of T1D but, unlike typical T1D, does not present acutely with DKA or an insulinrequiring diabetes emergency. Typically, they present $>30$ years of age, are independent of insulin at diagnosis for more than 6 months and have positive diabetes autoantibodies.

From an analysis of patients enrolled in the UKPDS trial, there was no significant difference in cardiovascular outcomes compared with patients with T2D, after adjustment for confounders. ${ }^{13}$ Patients with LADA were also seen to have a higher risk of microvascular complications compared with T2D, secondary to worse glycaemic control. Therefore, optimisation of glycaemic control and secondary prevention of diabetic complications should be an important aspect in the management of LADA. ${ }^{14}$

\section{Investigations}

As mentioned, positivity for diabetes autoantibodies is a feature of LADA, out of which, GAD65 antibody is the most sensitive with up to $90 \%$ of LADA patients positive. ${ }^{15}$ Therefore, GAD 65 antibody is a good screening antibody, and if there is still a strong suspicion of LADA in a GAD65 antibody negative patient, other diabetes autoantibodies should be assayed.

C-peptide, as a marker of endogenous insulin production, is useful to aid management (see later). With LADA, patients tend to have a low but still detectable level.

\section{Treatment}

Treatment of LADA is aimed at preserving insulin secretion capacity, commencing insulin when appropriate and standard secondary prevention of diabetic complications. Sulphonylureas can accelerate the decline of C-peptide levels and are not recommended for the treatment of LADA. ${ }^{12}$

A recent consensus statement from an international expert panel suggests the use of $\mathrm{C}$-peptide to guide management of LADA. C-peptide levels should be done concurrently with plasma glucose which should be between 4.4 to $10 \mathrm{mmol} / \mathrm{L}$. If C-peptide levels are $<300 \mathrm{pmol} / \mathrm{L}$, a multiple insulin regimen is recommended, and the patient should be treated as T1D. If C-peptide levels are between 300 to $700 \mathrm{pmol} / \mathrm{L}$, the patient should be treated like having T2D, avoiding the use of sulphonylureas. C-peptide levels should be repeated every 6 months here. If C-peptide levels are $>700$ pmol/L, treat like T2D and consider repeating C-peptide when there is a deterioration in glucose control. ${ }^{12}$

\section{Ketosis-prone diabetes}

Ketosis-prone diabetes is characterised by the presence of DKA in patients who do not fit the typical characteristics of T1D. After initial treatment with insulin and improvement in glycaemic control, there is frequently a marked improvement in beta cell function allowing discontinuation of insulin therapy within a few months. ${ }^{16}$ In these patients, there is an acute reduction in insulin secretion and action due to glucose toxicity on the beta cells. Treatment with insulin can improve hyperglycaemia and beta cell function and therefore, ceasing the need for further insulin treatment within a few months.

This is more commonly seen in people of non-White ethnicity, particularly Black African or African-Caribbean people and shows a strong male predominance, strong family history, higher age and higher body mass index. ${ }^{17,18}$ There is also a link between glucose-6phosphate dehydrogenase deficiency (a condition that is frequent in male West Africans) and ketosis-prone diabetes. ${ }^{19}$

It is important to recognise this clinical entity as continuation of unnecessary insulin could cause further weight gain, hypoglycaemia and impact quality of life. Furthermore, incorrectly diagnosing these patients with T2D could neglect the importance of checking ketones when unwell.

\section{Investigations and management}

DKA should be managed as per DKA protocols and all patients should be discharged on insulin. Following discharge, patients should be followed up by the diabetes team to reassess beta cell function with C-peptide measurements and to assess autoimmunity. They must have a negative autoantibody profile. 
Table 3. Clinical and biochemical features of T1D, T2D, LADA, MODY, ketosis-prone diabetes

\begin{tabular}{|c|c|c|c|c|c|}
\hline & T1D & T2D & MODY & LADA & Ketosis-prone diabetes \\
\hline Age of onset & $\begin{array}{l}\text { Childhood/ } \\
\text { adolescence }\end{array}$ & Adulthood & $<30$ years old & $30-50$ years old & Adulthood \\
\hline Ethnicity & $\begin{array}{l}\text { More common in } \\
\text { White people }\end{array}$ & $\begin{array}{l}\text { More common in } \\
\text { Asian people }\end{array}$ & Prevalence not known & $\begin{array}{l}\text { More common in } \\
\text { White people }\end{array}$ & $\begin{array}{l}\text { More common in } \\
\text { Black African/African- } \\
\text { Caribbean people }\end{array}$ \\
\hline $\begin{array}{l}\text { Insulin } \\
\text { requirement }\end{array}$ & At diagnosis & $\begin{array}{l}\text { Absent or years } \\
\text { after diagnosis }\end{array}$ & Variable & $\begin{array}{l}>6 \text { months after } \\
\text { diagnosis }\end{array}$ & $\begin{array}{l}\text { If DKA / low C-peptide } \\
\text { levels }\end{array}$ \\
\hline BMI & Variable & Increased & Variable & Variable & Increased \\
\hline $\begin{array}{l}\text { Diabetes } \\
\text { autoantibodies }\end{array}$ & High titre & Absent & Absent & High/low titre & Absent \\
\hline $\begin{array}{l}\text { C-peptide levels } \\
5 \text { years post- } \\
\text { diagnosis }\end{array}$ & Usually $<300 \mathrm{pmol} / \mathrm{L}$ & Normal/increased & Usually >300 pmol/L & $\begin{array}{l}\text { Decreased but } \\
\text { still detectable }\end{array}$ & Variable \\
\hline
\end{tabular}

Typically, C-peptide levels are low at the time of DKA and increase within a few weeks/months. ${ }^{18}$

In patients with sufficient C-peptide in comparison to their paired glucose level, insulin can be safely discontinued in the majority of patients. They can manage with diet or metformin for some years but can relapse with DKA. Patients with insufficient C-peptide in comparison with their paired glucose level will need to continue insulin therapy. ${ }^{20}$

\section{Secondary causes of diabetes}

There are many secondary causes of diabetes as highlighted in Table 1. Although much less common, it is important to recognise them so that the primary disease can be treated promptly. We discuss two important causes of secondary diabetes.

\section{Pancreatic cancer}

Pancreatic cancer may rarely present with hyperglycaemia due to pancreatic dysfunction from the cancer. Consider screening with computed tomography (CT) for pancreatic cancer if there is new-onset T2D in older people with marked weight loss, loss of appetite, abdominal pain or features of exocrine insufficiency.

\section{Haemochromatosis}

Haemochromatosis can present with hyperglycaemia due to iron deposition in the pancreas. There should be a clinical suspicion if there is skin hyperpigmentation, joint pain, hypogonadism or features of liver disease. Laboratory tests that may be associated with haemochromatosis are unexplained liver function abnormalities, high serum ferritin and high transferrin saturations. Diagnosis will come from HFE gene mutation tests. Treatment of diabetes in haemochromatosis is similar to T2D and can sometimes also be improved with phlebotomy. ${ }^{21}$

\section{Conclusion}

Diabetes is a common condition and affects a large proportion of people that we see in clinical practice. Although the general physician will be familiar with the presentations of T2D and T1D, it is important to consider other uncommon forms of diabetes and, if the presenting features are atypical, to involve the local diabetes team at an early stage (Table 3 ).

\section{References}

1 DiabetesUK. Diabetes statistics. Diabetes UK. www.diabetes.org.uk/ professionals/position-statements-reports/statistics [Accessed 11 May2020].

2 American Diabetes Association. Diagnosis and classification of diabetes mellitus. Diabetes Care 2014;37(Suppl 1):81-90.

3 Shields BM, Hicks S, Shepherd MH et al. Maturity-onset diabetes of the young (MODY): How many cases are we missing? Diabetologia 2010:53:2504-8.

4 Thanabalasingham G, Owen KR. Diagnosis and management of maturity onset diabetes of the young (MODY). BMJ 2011;343:d6044.

5 Stride A, Ellard S, Clark P et al. $\beta$-cell dysfunction, insulin sensitivity, and glycosuria precede diabetes in hepatocyte nuclear factor- $1 \alpha$ mutation carriers. Diabetes Care 2005;28:1751-6.

6 Steele AM, Shields BM, Shepherd M et al. Increased all-cause and cardiovascular mortality in monogenic diabetes as a result of mutations in the HNF1A gene. Diabet Med 2010;27:157-61.

7 Steele AM, Shields BM, Shepherd M et al. Microvascular complication risk in patients with 50 years of moderate hyperglycemia: are target ranges for glycemia control appropriate? Diabet Med 2011;28(S1):2.

8 Steele AM, Shields BM, Wensley KJ et al. Prevalence of vascular complications among patients with glucokinase mutations and prolonged, mild hyperglycemia. JAMA 2014;311:279-86.

9 Gupta RK, Vatamaniuk MZ, Lee CS et al. The MODY1 gene HNF-4 $\alpha$ regulates selected genes involved in insulin secretion. J Clin Invest 2005;115:1006-15.

10 Besser RE], Shepherd MH, McDonald T] et al. Urinary C-peptide creatinine ratio is a practical outpatient tool for identifying hepatocyte nuclear factor $1-\alpha /$ hepatocyte nuclear factor $4-\alpha$ maturityonset diabetes of the young from long-duration type 1 diabetes. Diabetes Care 2011;34;286-91.

11 Naik RG, Brooks-Worrell BM, Palmer JP. Latent autoimmune diabetes in adults. J Clin Endocrinol Metab 2009;94:4635-44.

12 Buzzetti R, Tuomi T, Mauricio D et al. Management of latent autoimmune diabetes in adults: A consensus statement from an international expert panel. Diabetes 2020;69:2037-47. 
13 Maddaloni E, Coleman RL, Pozzilli P, Holman RR. Long-term risk of cardiovascular disease in individuals with latent autoimmune diabetes in adults (UKPDS 85). Diabetes, Obes Metab 2019;21:2115-22.

14 Maddaloni E, Coleman RL, Agbaje O, Buzzetti R, Holman RR. Time-varying risk of microvascular complications in latent autoimmune diabetes of adulthood compared with type 2 diabetes in adults: a post-hoc analysis of the UK Prospective Diabetes Study 30-year follow-up data (UKPDS 86). Lancet Diabetes Endocrinol 2020;8:206-15.

15 Hawa MI, Kolb H, Schloot $\mathrm{N}$ et al. Adult-onset autoimmune diabetes in Europe is prevalent with a broad clinical phenotype: Action LADA 7. Diabetes Care 2013;36:908-13.

16 Mauvais-Jarvis F, Sobngwi E, Porcher R et al. Ketosis-prone type 2 diabetes in patients of Sub-Saharan African origin: clinical pathophysiology and natural history of $\beta$-cell dysfunction and insulin resistance. Diabetes 2004;53:645-53.

17 Balasubramanyam A, Zern JW, Hyman DJ, Pavlik V. New profiles of diabetic ketoacidosis: Type 1 vs type 2 diabetes and the effect of ethnicity. Arch Intern Med 1999;159:2317-22.
18 Smiley D, Chandra P, Umpierrez GE. Update on diagnosis, pathogenesis and management of ketosis-prone Type 2 diabetes mellitus. Diabetes Manag 2011;1:589-600.

19 Sobngwi E, Gutier J-F, Kevorkian J-P et al. High prevalence of glucose-6-phosphate dehydrogenase deficiency without gene mutation suggests a novel genetic mechanism predisposing to ketosis-prone diabetes. J Clin Endocrinol Metab 2005;90;4446-51.

20 Balasubramanyam A, Garza G, Rodriguez L et al. Accuracy and predictive value of classification schemes for ketosis-prone diabetes. Diabetes Care 2006;29:2575-9.

21 Barton JC, Acton RT. Diabetes in HFE Hemochromatosis. J Diabetes Res 2017; 2017:9826930

Address for correspondence: Dr Mohammed Huda, Department of Diabetes, John Harrison House, The Royal London Hospital, Whitechapel, London E1 1FR, UK. Email: bobby.huda1@nhs.net 